\title{
Association of single nucleotide polymorphism of 5- flanke ghrelin gene with obesity in Saudi subjects
}

\author{
Tarek Mohamed Ali*1-2 , Ayman Saied Alhazmi ${ }^{1}$, Amany Salah Khalifa ${ }^{3-4}$ \\ ${ }^{1}$ Clinical Laboratory Department, Faculty of Applied Medical Sciences, Taif University, Saudi Arabia. \\ ${ }^{2 *}$ Physiology Department, Faculty of Medicine, Beni Suef University, Egypt. \\ 3. Clinical Laboratory Department, Faculty of Pharmacy, Taif University, Saudi Arabia. \\ ${ }^{4}$ Clinical pathology Department, Faculty of Medicine, Menoufia University, Egypt
}

\begin{abstract}
:
Context: Numerous variations in ghrelin gene have been established to be associated with obesity parameters and ghrelin level.

Aims: to focus on single nucleotide polymorphism (SNP) 501A>C in ghrelin gene and study the association of its different genotypes with certain obesity parameters and examine the relationship of these genotypes with ghrelin levels.
\end{abstract}

Settings and Design: The study included 88 unrelated obese subjects recruited from the outpatient clinics in king Abdul-Aziz hospital, Taif, KSA. Age and sex matched 56 unrelated healthy subjects serving as healthy controls.

Methods and Material: Waist circumferences (WC) were measured and the body mass index (BMI) was calculated. Fasting serum leptin and ghrelin levels were determined using commercially available ELISA kits. SNP 501A>C in ghrelin gene was studied by restriction fragment length polymorphism (RFLP).The DNA fragment containing the SNP was amplified by PCR.

Statistical analysis used: One-way analysis of variance (ANOVA) and simple linear regression analysis were analyzed using Package for Social Sciences (SPSS) software for Windows (version 12.0; SPSS Inc., Chicago, IL, USA).

Results: BMI and WC were not significantly different in the SNP genotypes of both groups. In the obese group, Ghrelin level was significantly different in both groups regarding the three SNP genotypes. Ghrelin levels may be associated with $-501 A>A$ and $-501 A>C$ genotypes in obese.

Conclusions: Anthropometric parameters were not significantly different in the SNP genotypes of both groups, while ghrelin level was significantly different regarding the three SNP genotypes. Ghrelin levels may be associated with $-501 A>C$ variant in obese.

Key-words: Single nucleotide polymorphism - 5-flanke ghrelin gene - obesity -Saudi subjects

\section{Introduction:}

Obesity and overweight are increasing rapidly worldwide and now represents a major health crisis. Obesity determined by body mass index (BMI) $>30 \mathrm{~kg} / \mathrm{m} 2$ is strongly associated with several co-morbidities such as type 2 diabetes, hypertension, dyslipidaemia, atherosclerosis, stroke and furthermore, it is connected with increased rate of mortality. The major factors contributing to the epidemic of obesity are believed to be the sedentary lifestyle; decreased physical activity, and the popularity of energy rich foods. However, some individuals gain weight more easily and are more vulnerable to the obesogenic environment of today's world than others. These differences are probably due to their genetic or biological predisposition towards obesity ${ }^{[1]}$. Therefore it is of considerable importance to identify the metabolic and genetic factors contributing to the risk for obesity and its co-morbidities. The ghrelin pathway has emerged over the last decade as a novel endocrine pathway involved in the control of feeding behavior and energy homeostasis, operating in parallel to the leptin and adiponectin circuits ${ }^{[2-5]}$. Ghrelin is a 28 amino-acid peptide with a fatty acid chain modification on the Nterminal third amino acid by the ghrelin O-acyltransferase enzyme ${ }^{[6]}$. It has a widespread tissue expression but the main source of circulating ghrelin is the gastric mucosa ${ }^{[7]}$. Ghrelin has a role in growth hormone regulation ${ }^{[8]}$ but in the recent years the majority of the data have shown its effects on appetite regulation via the hypothalamus ${ }^{[9]}$ and the brain stem and influence on the peripheral metabolism, especially the carbohydrate and lipid metabolism ${ }^{[10]}$. Ghrelin is a factor involved in meal initiation which acts on the hypothalamus via the ghrelin receptor ${ }^{[11]}$. Serum ghrelin levels are augmented by fasting and decreased by refeeding or oral glucose intake, ${ }^{[12]}$. In humans, ghrelin levels have a diurnal rhythm which is the same as the diurnal rhythm of leptin, with both hormones increasing throughout the day to a peak at $01.00 \mathrm{~h}$, then falling overnight to a lowest point at $09.00 \mathrm{~h}^{[11]}$. Circulating ghrelin levels show pre-prandial rise and fall rapidly postprandially ${ }^{[11]}$. circulating 
ghrelin levels are negative correlated with body mass index in human. It has been reported that fasting plasma levels of ghrelin were high in patients with anorexia nervosa ${ }^{[13]}$ also in subjects with diet induced weight loss. on the contrary, obese subjects show a less marked drop in plasma ghrelin after meal ingestion ${ }^{[14]}$. A deeper understanding on this interesting pleiotropic hormone could be anticipated to open new insights into the metabolic pathways causing a predisposition for obesity and its co-morbidities.The ghrelin gene has been a candidate gene in several studies focusing on the genetic variations underlying obesity and growth. Several variations have been found to be associated with obesity related parameters. In the present study, the aims were to focus on single nucleotide polymorphism (SNP) 501A $>\mathrm{C}$ in ghrelin gene and study the association of its different genotypes with certain obesity parameters and examine the relationship of these genotypes with ghrelin levels.

\section{Subjects and Methods: \\ 1.1 Study population}

The study included 88 unrelated obese subjects recruited consecutively from those whom were treated and followed up in the outpatient clinics in king Abdul-Aziz hospital Taif, KSA. Age and sex matched 56 unrelated healthy subjects, selected staffs and students in our institute, were recruited consecutively, serving as healthy controls. All patients and healthy subjects were of Saudi origin, from Taif region in KSA. The protocol of this study was approved by the institutional Ethics Committee of College of Applied Medical Sciences, Taif University and all the participants gave their informed consent before participation in the study. Detailed medical histories of all the participants were obtained, and their systemic examinations were carried out. Participants who had a history of digestive, endocrine, metabolic diseases, eating disorders or any other psychiatric disease were eliminated from the study. Blood pressure and anthropometric parameters were measured by a trained nurse and the BMI was calculated as weight in kilograms divided by the height (in meters) squared. Waist circumferences were measured by trained personnel using a tape measure.

\subsection{Leptin and ghrelin levels assay}

Fasting serum leptin levels were determined for two groups using a commercially available leptin ELISA kit (DRG international, USA). Each sample was run in duplicate within the same plate and a coefficient of variation was calculated.The average of the two leptin measurements was used for this analysis. Plasma ghrelin concentrations were measured using ELISA kits (DRG international, USA).

\subsection{Genotyping of the ghrelin gene variants:}

Single nucleotide polymorphism (SNP) 501A $>\mathrm{C}$ (rs26802) in promoter ghrelin gene was studied by restriction fragment length polymorphism (RFLP).The DNA fragment containing the SNP was amplified by PCR as described by Vartiainen et al ${ }^{[15]}$ then the PCR product was digested with $0.025 \mathrm{U}$ MwoI restriction enzyme (New England Biolabs). The mixture was incubated at $608 \mathrm{C}$ for 16 hours. The digestion of the DNA fragment consisting of 509 base pairs (bp) resulted in 136- and 372-bp fragments in the 501A/A genotypes, and in the 501C/C genotype, the 372-bp fragment was further digested into 241 - and $141 \mathrm{bp}$ fragments. The primers used are shown in table (1). The digestion fragments were separated and visualized on an ultraviolet transluminator after electrophoresis on a $2 \%$ agarose gel (QA agar) containing $2 \mathrm{ng} / \mathrm{mL}$ ethidium bromide Vartiainen et al ${ }^{[15]}$.

\subsection{Statistical analysis}

Data are expressed as the mean $\pm \mathrm{SD}$. Each variable was assessed for a normal distribution using the Kolmogorov- Smirnov test. Statistical differences between the groups were identified using one-way analysis of variance (ANOVA). Simple linear regression analysis with the genotype as a dependent variable was performed to identify its relation to ghrelin level. All statistical results were based on two-sided tests. Data were analyzed using Package for Social Sciences (SPSS) software for Windows (version 12.0; SPSS Inc., Chicago, IL, USA). P $<0.05$ was regarded as significant.

\section{Results:}

A Saudi case control study comprising of 88 obese subjects and 56 controls was done and genotyped for restriction fragment length polymorphism SNP $-501 \mathrm{~A}>\mathrm{C}$ of 5 flanke ghrelin gene by sequencing 144 DNA samples and 3 genotypes were observed, $-501 \mathrm{~A}>\mathrm{A},-501 \mathrm{~A}>\mathrm{C}$ and $-501 \mathrm{C}>\mathrm{C}$ (Fig.1). The SNP genotype distribution pattern was in agreement with Hardy-Weinberg equation. The observed wild $-501 \mathrm{~A}>\mathrm{A}$ and homozygote $-501 \mathrm{C}>\mathrm{C}$ genotypes were more common than expected in both study groups. No significant differences were observed in allele frequencies between the obese and the control group in the SNP $-501 \mathrm{~A}>\mathrm{C}$ of 5 flanke ghrelin gene OR 95\% CI 0.93 (0.78-1.10) (table 2). As shown in Fig.2, no significant differences were observed regarding age in different genotypes in both study groups ( $>0.05)$. BMI was not significantly 
different in the SNP genotypes of both control and obese subjects ( $\mathrm{p}=0.075,0.091)$ respectively. In control group, WC revealed no significant differences in between SNP genotypes, while in obese group, it reached a borderline statistical significance $(\mathrm{p}=0.055)$. The $-501 \mathrm{C}>\mathrm{C}$ genotype was associated with the lowest and $501 \mathrm{~A}>\mathrm{C}$ genotype with the highest ghrelin level in control group. Moreover, in the obese group, the $-501 \mathrm{~A}>\mathrm{A}$ wild genotype was associated with the lowest and $-501 \mathrm{C}>\mathrm{C}$ genotype with the highest ghrelin levels. Ghrelin level was significantly different in both control and obese groups regarding the three SNP genotypes $(\mathrm{p}=0.000$, 0.025 ) respectively, while leptin levels were not significantly different in the SNP genotypes in both control and obese subjects $(\mathrm{p}=0.595,0.248)$ respectively. Linear regression analysis showed that ghrelin levels may be associated with $-501 \mathrm{~A}>\mathrm{A}$ genotype in obese $(\mathrm{p}=0.007)$ but not in control group $(\mathrm{p}=0.757)$ while, $-501 \mathrm{~A}>\mathrm{C}$ genotype in both control and obese groups was associated with ghrelin level $(\mathrm{p}=.012$ and .018$)$. The $-501 \mathrm{C}>\mathrm{C}$ genotype was negatively associated with ghrelin level in control $(\mathrm{p}=0.000)$ not in obese subjects $(\mathrm{p}=0.438)$ (table 3).

Table 1: Locations and primer sequences of SNP analyzed.

\begin{tabular}{|l|l|l|}
\hline Variants & Locations & Primers \\
\hline $\begin{array}{l}\text { A-501C } \\
\text { (rs26802) }\end{array}$ & Promoter & F: 5'-agaacaaacgccagtcatcc-3 \\
R: 5'-gtcttccagccagacagtcc-3'
\end{tabular}

SNPs: single nucleotide polymorphisms; F, R: forward and reverse primer sequences.

Table 2: Single nucleotide polymorphism association analysis of the ghrelin gene.

\begin{tabular}{|c|c|c|c|c|c|c|c|}
\hline Loci & $\begin{array}{l}\text { Allele/ } \\
\text { genotype }\end{array}$ & Control & Case & HWE & $\begin{array}{l}\text { Control } \\
\text { genotype } \\
\text { frequencies }\end{array}$ & $\begin{array}{l}\text { Case } \\
\text { genotype } \\
\text { frequencies }\end{array}$ & OR 95\% CI \\
\hline \multirow{3}{*}{$\begin{array}{l}\mathrm{C}-501 \mathrm{~A} \\
\mathrm{rs} 26802\end{array}$} & AA & 32 & 52 & \multirow[t]{3}{*}{0.155} & 57.14 & 59.1 & \multirow{3}{*}{$0.93(0.78-1.10)$} \\
\hline & $\mathrm{CA}$ & 16 & 28 & & 28.57 & 31.8 & \\
\hline & $\mathrm{CC}$ & 8 & 8 & & 14.29 & 9.1 & \\
\hline
\end{tabular}

Table 3: Coefficients of regression analysis to determine the relationship between ghrelin level and different ghrelin gene SNP genotypes in control and obese group.

\begin{tabular}{|l|l|l|l|l|l|l|l|l|}
\hline & \multicolumn{4}{|l|}{ Control group } & \multicolumn{2}{l|}{ Obese group } \\
\hline & Beta & \multicolumn{2}{l|}{ Confidence level } & Sig. & Beta & \multicolumn{2}{l|}{ Confidence level } \\
\hline AA & .042 & -43.27 & 46.85 & .757 & .287 & 18.13 & 109.12 & .007 \\
\hline CA & .333 & 6.21 & 48.14 & .012 & -.252 & -53.67 & -5.15 & .018 \\
\hline CC & -.490 & -51.07 & -17.71 & .000 & -.084 & -37.547 & 16.414 & .438 \\
\hline
\end{tabular}

Figure 1:

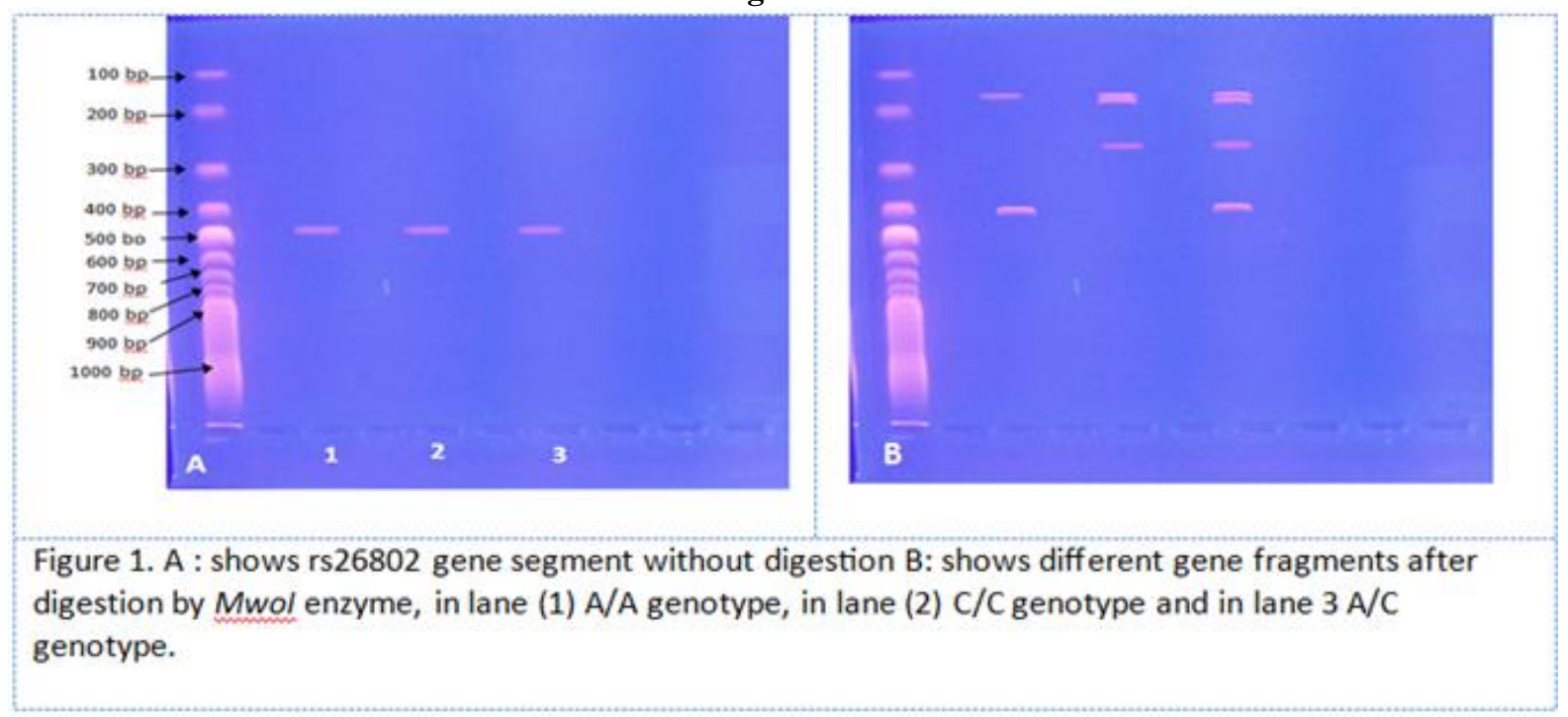


Figure 2:

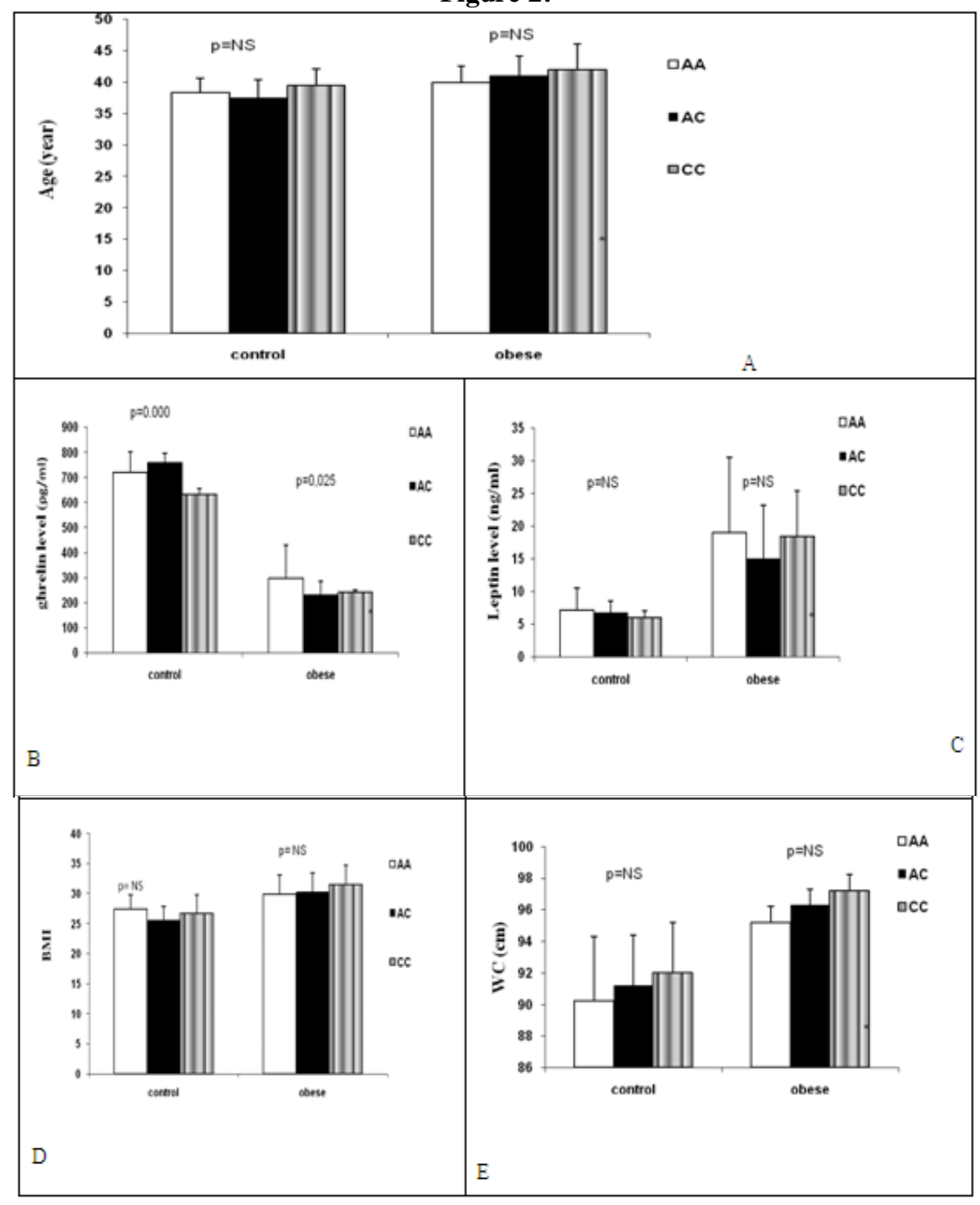

Figure 2: ANOVA study to explain the statistical differences between the 3 different SNPs in control and obese subjects regarding age, ghrelin level, leptin level, Body Mass Index (BMI) and waist circumference (WC). panel A :shows no significant differences regarding age in different genotypes in both study groups $(\mathrm{p}>0.05)$. Panel B: The $-501 \mathrm{C}>\mathrm{C}$ genotype was associated with the lowest and $-501 \mathrm{~A}>\mathrm{C}$ genotype with the highest ghrelin level in control group. Moreover, in the obese group, the $-501 \mathrm{~A}>\mathrm{A}$ wild genotype was associated with the lowest and $-501 \mathrm{C}>\mathrm{C}$ genotype with the highest ghrelin levels. Ghrelin level was significantly different in both control and obese groups regarding the three SNP genotypes $(\mathrm{p}=0.000,0.025)$ respectively. Panel C: leptin levels were not significantly different in the SNP genotypes in both groups $(\mathrm{p}=0.595,0.248)$ respectively. Panel D: BMI was not significantly different in the SNP genotypes of both control and obese subjects $(\mathrm{p}=0.075,0.091)$ respectively. Panel $\mathrm{E}$ : In control group, WC revealed no significant differences in between SNP genotypes, while in obese group, it reached a borderline statistical significance $(\mathrm{p}=0.055)$.

\section{Discussion:}

The ghrelin gene has been considered as a candidate gene in numerous studies focusing on the genetic variations underlying obesity and growth. There is a growing body of evidence, that variations in the ghrelin gene might correlate with obesity and its co-morbidities but there are discrepancies between the different studies conducted in different populations. In the present study, wild $-501 \mathrm{~A}>\mathrm{A}$ and homozygote $-501 \mathrm{C}>\mathrm{C}$ genotypes were more common than expected in both study groups. No significant differences were observed either in allele frequencies between the obese and the control group or in age of men and women in the different SNP -501A $>C$ of 5 flanke ghrelin gene. As a comparison, Martin et al ${ }^{[16]}$ classified their subjects according to BMI, which 
only provides an estimation of adiposity. Upon analysis of their results, they found no significant differences of allele frequencies for any SNP investigated between the lean and obese groups when classified according to BMI. In our study, neither BMI nor WC was not significantly different in the SNP genotypes of both control and obese subjects. A non-significant trend of obese subjects with $-501 \mathrm{C} / \mathrm{C}$ genotype having the highest and 501A/A genotype having the lowest BMI was found. The difference was not significant when the three genotypes were compared in analysis of variance. Our study was in agreement with the OPERA study where there were no significant association of $-501 \mathrm{~A}>\mathrm{C}$ genotype with $\mathrm{BMI}$ except when $\mathrm{A} / \mathrm{C}$ and $\mathrm{C} / \mathrm{C}$ are combined and compared with A/A genotype ${ }^{[15]}$. The Finnish study identified 11 SNPs, of which the $-501 \mathrm{~A}>\mathrm{C}$ sequence variation showed borderline statistical significance for lower BMI $(\mathrm{p}=0.055)$. The borderline significant association with the SNP $-501 \mathrm{~A}>\mathrm{C}$ and BMI was maintained in the OPERA study population even after adjustments. Fascinatingly, this SNP was studied further in a large population of Central Europeans. There was a non-significant trend of this SNP $-501 \mathrm{~A}>\mathrm{C}$ variant to be associated with higher BMI, but no significant associations were found ${ }^{[17]}$. This suggests that the significance of this SNP with BMI or weight regulation is doubtful to be dramatic. On the other hand, single genetic factors contributing to the susceptibility for weight gain are likely to have a very small effect. It is the combined effects of several factors that determine the overall risk. WC revealed no significant differences in between SNP genotypes in ANOVA study to find out the significant differences in between the SNP genotypes. In a previous study, male but not female carriers of the 501A allele also had higher mean waist circumference than subjects homozygous for the minor allele ${ }^{[15]}$. Ghrelin level was significantly different in the three SNP genotypes of both study groups, while leptin levels were not. Moreover, in the obese group, the $-501 \mathrm{~A}>\mathrm{A}$ wild genotype was associated with the lowest and $501 \mathrm{C}>\mathrm{C}$ genotype with the highest ghrelin levels. Linear regression analysis showed that ghrelin levels may be associated with -501A>A genotype in obese. In a previous study of Vartiainen et a ${ }^{[15]}, \mathrm{C}$ allele carriers of the $-501 \mathrm{~A}>\mathrm{C}$ SNP (GHRL) were shown to have higher fasting ghrelin levels than subjects with the AA genotype ${ }^{[15]}$. In humans, increased plasma ghrelin levels are recognized to initiate individual meals ${ }^{[18]}$ and enhance food intake ${ }^{[19]}$. Mageret et al ${ }^{[20]}$ has been shown that the SNP $-501 \mathrm{~A}>\mathrm{C}$ was associated with ghrelin expression in human peripheral blood mononuclear cells, with the $-501 \mathrm{C}>\mathrm{C}$ genotype having the lowest and $-501 \mathrm{~A} / \mathrm{A}$ genotype having the highest ghrelin mRNA expression. On account of fasting plasma ghrelin levels, CC homozygous subjects are at increased risk for overeating. Though, they had a lower BMI and tended to have a lower waist circumference than the AC and AA genotypes ${ }^{[15]}$ suggesting an adequate food intake regulation. This contradiction may be explained by a relationship observed in the study of den Hoed et al ${ }^{[21]}$; subjects with CC genotype have a high postprandial response in the (an) orexigenic hormone peptide YY (PYY) compared with AA genotype subjects.

\section{Conclusions}

BMI was not significantly different in the SNP genotypes of both control and obese subjects. The $501 \mathrm{C}>\mathrm{C}$ genotype was associated with the lowest and $-501 \mathrm{~A}>\mathrm{C}$ genotype with the highest ghrelin level in control group. Moreover, in the obese group, the $-501 \mathrm{~A}>\mathrm{A}$ wild genotype was associated with the lowest and $501 \mathrm{C}>\mathrm{C}$ genotype with the highest ghrelin levels. Ghrelin level was significantly different in both control and obese groups regarding the three SNP genotypes. This may suggest that $-501 \mathrm{~A}>\mathrm{A}$ wild genotype may be associated with low ghrelin level in obese people but this SNP is not associated with BMI or with WC.

\section{Acknowledgment:} $1 / 434 / 2722$

The authors would like to thank Taif University for funding this work as an accepted project number

\section{References}

[1]. World Health Organization. Obesity: preventing and managing the global epidemic. Report of a WHO consultation: World Health Organization Technical Report series 2000;894.

[2]. Howard AD, Feighner SD, Cully DF, Arena JP, Liberator PA, Rosenblum CI, et al. A receptor in pituitary and hypothalamus that functions in growth hormone release. Science ,273(5277), 1996, 974-977.

[3]. Kojima M, Hosoda H, Date Y, Nakazato M, Matsuo H, Kangawa K. Ghrelin is a growth-hormone-releasing acylated peptide from stomach. Nature ,402, 1999, 656-660.

[4]. Tschop M, Smiley DL, Heiman ML. Ghrelin induces adiposity in rodents. Nature ;407, 2000, 908-913.

[5]. Zhang JV, Ren PG, Avsian-Kretchmer O, Luo CW, Rauch R, Klein C, et al. Obestatin, a peptide encoded by the ghrelin gene, opposes ghrelin's effects on food intake. Science;310, 2005:996-9.

[6]. Yang J, Brown MS, Liang G, Grishin NV, Goldstein JL. Identification of the acyltransferase that octanoylates ghrelin, an appetitestimulating peptide hormone. Cell , 132, 2008,387-396.

[7]. Korbonits M, Goldstone AP, Gueorguiev M, Grossman AB. Ghrelin - a hormone with multiple functions. Frontiers in Neuroendocrinology, 25, 2004, 27-68.

[8]. Nass R, Farhy LS, Liu J, Prudom CE, Johnson ML, Veldhuis P, et al. Evidence for acyl-ghrelin modulation of growth hormone release in the fed state. Journal of Clinical Endocrinology and Metabolism , 93,2008: 1988-1994. 
[9]. Kola B, Korbonits M. Shedding light on the intricate puzzle of ghrelin's effects on appetite regulation. Journal of Endocrinology, 202, 2009,1-9.

[10]. Higgins SC, Gueorguiev M, Korbonits M. Ghrelin, the peripheral hunger hormone. Annals of Medicine, 39, 2007,116-136.

[11]. Cummings DE, Purnell JQ, Frayo RS, Schmidova K, Wisse BE, Weigle DS. A preprandial rise in plasma ghrelin levels suggests a role in meal initiation in humans. Diabetes, $50,2001,1714-1719$.

[12]. Tschop M, Smiley DL, Heiman ML. Ghrelin induces adiposity in rodents. Nature. 407,2000, 908-13.

[13]. Otto B, Cuntz U, Fruehauf E, Wawarta R, Folwaczny C, Riepl RL, et al. Weight gain decreases elevated plasma ghrelin concentrations of patients with anorexia nervosa. European Journal of Endocrinology, 145, 2001:669-673.

[14]. Cummings DE, Weigle DS, Frayo RS, Breen PA, Ma MK, Dellinger EP, et al. Plasma ghrelin levels after diet-induced weight loss or gastric bypass surgery. The New England Journal of Medicine. 346, 2002, 1623-1630.

[15]. Vartiainen J, Kesaniemi YA, Ukkola O. Sequencing analysis of ghrelin gene 5_ flanking region: relations between the sequence variants, fasting plasma total ghrelin concentrations, and body mass index. Metabolism; 55, 2006, 1420-1425.

[16]. Martin GR, Loredo JC, Sun G.Lack of association of ghrelin precursor gene variants and percentage body fat or serum lipid profiles. Obesity (Silver Spring). 16(4),2008; 908-912.

[17]. Hubacek JA, Adamkova V, Bohuslavova R, Suchanek P, Poledne R, Lanska V. No significant association between -A501C single nucleotide polymorphism in preproghrelin and body mass index or waist-to-hip ratio in central European population. Metab Clin Exp 57, 2008, 1016-1017.

[18]. Cummings DE, Purnell JQ, Frayo RS, Schmidova K, Wisse BE, Weigle DS. A preprandial rise in plasma ghrelin levels suggests a role in meal initiation in humans. Diabetes 50,2001, 1714-1719

[19]. Wren AM, Seal LJ, Cohen MA, Brynes AE, Frost GS, Murphy KG et al. Ghrelin enhances appetite and increases food intake in humans. J Clin Endocrinol Metab; 86, 2001, 5992

[20]. Mager U, Kolehmainen M, de Mello VDF, Schwab U, Laaksonen DE, Rauramaa R, et al. Expression of ghrelin gene in peripheral blood mononuclear cells and plasma ghrelin concentrations in patients with metabolic syndrome. Eur J Endocrinol; 158, 2008, 499510 .

[21]. den Hoed M, Smeets A, Veldhorst MAB, Nieuwenhuizen AG, Bouwman FG, Heidema AG, et al. SNP analyses of postprandial responses in (an) orexigenic hormones and feelings of hunger reveal long-term physiological adaptations to facilitate homeostasis. Int J Obes,32, 2008,1790-1798. 